\title{
Existe o Direito de Ação?
}

\author{
Luís Eulalio de Bueno Vidigal \\ Catedrático de Direito Processual Civil na \\ Faculdade de Direito da Universidade de \\ São Paulo.
}

1. Decorrido mais de um século sôbre o início da controvérsia, que parece destinada a nunca terminar, a respeito do direito de ação, o título dêste estudo pode, à primeira vista, parecer ditado pela preocupação de impressionar pela novidade e pela falsa originalidade.

Se, entretanto, submetermos à crítica algumas proposições dos mais notáveis mestres da ciência do Direito Processual Civil moderno, para logo veremos que, longe de buscar surpreender o leitor com opiniões bizarras, nada mais visamos senão recolocar em seus devidos têrmos um problema que as doutrinas mais variadas e engenhosas acabaram por situar no domínio dos mistérios inaccessíveis à compreensão do homem comum e, mais do que isso, à do próprio homem de ciência.

2. É duvidoso - afirma Chiovenda - que exista um direito à tutela jurídica contra o Estado, o que suporia conflito de interêsses entre Estado e cidadão, pois dar razāo a quem a tem é interêsse do Estado, e é um interêsse a que provê permanentemente com a instituição dos juízes ${ }^{1}$.

Nega, portanto, Chiovenda que exista direito do particular contra o Estado e, ao conceber a ação como direito

1. Istituzioni, 6 . 
potestativo dirigido contra o adversário, omite pura e simplesmente qualquer justificativa jurídica para o poder de exigir, do Poder Público, tôda a atividade necessária para a outorga da prestação jurisdicional.

3. Carnelutti também faz afirmações que fàcilmente nos levam a hesitar em qualificar de direito a situação pela qual alguém tem a possibilidade de movimentar o aparelho jurisdicional do Estado: "a diferença entre direito subjetivo e faculdade encontra-se na que existe entre agere e jubere; a faculdade não sai da esfera do interêsse próprio, ao passo que o direito subjetivo invade a esfera do interêsse alheio". "A um particular pode caber um direito subjetivo público, como é, por exemplo, o direito de ação" ${ }^{2}$.

Confrontem-se essas afirmações com esta do Sistema: "O interêsse protegido mediante as obrigações processuais e, correspondentemente mediante a ação, é o interêsse à justa composição da lide (pág. 890).

Ora, se o direito subjetivo é proteção de interêsses em conflito e se a ação é proteção do interêsse do particular à justa composição da lide, onde a esfera do interêsse alheio a ser invadida pelo direito subjetivo do autor? Seja o Estado o titular passivo da relação processual, seja a pessoa física do juiz, ninguém se encontra, no lado passivo da relação, que tenha interêsse contrário à justa composição da lide.

4. O autor quer a satisfação de seu interêsse em conflito; o réu quer a de interêsse oposto. Não se pode dizer que a qualquer dêles interesse a composição da lide senão na medida em que essa composição favoreça seu interêsse material em conflito. Portanto, se a ação é a possibilidade de realizar o interêsse à justa composição da lide, temos de admitir que não é o autor o titular dela.

2. Teoria generale del diritto, $3 .^{a}$ ed., Roma, 1951, ps. 160 e 161. 
5. Alexandre Pekelis, mais cauteloso do que Chiovenda e Carnelutti, não aceita, como ponto de partida, o postulado de que a ação seja um direito subjetivo. Sua indagação primeira baseia-se precisamente na recusa dêsse postulado. Há dois pontos firmes, sustenta, comuns a todos os autores e doutrinas que cuidaram da ação.

Primeiro, todos admitem que a ação seja uma certa situação de vantagem, na qual se encontra o particular em relação à atividade jurisdicional do Estado.

Segundo, todos confrontam a ação com as demais situações de vantagem existentes nos vários ordenamentos jurídicos e principalmente com a mais importante delas que é a que se designa com o nome de direito subjetivo ${ }^{3}$.

6. Encontramos, pois, em Chiovenda, em Carnelutti e Pekelis, proposições que nos levam à admissibilidade da tese que, sob forma interrogativa, é objeto dêste estudo e lhe constitui o titulo.

Chrovenda nega a existência do direito de ação contra o Estado, porque êste não tem interêsse em negar razão a quem a tem. Concebendo a ação como direito potestativo contra o réu, não nos dá a natureza jurídica do poder que tem o particular de movimentar o aparelho jurisdicional do Estado.

Carnelutti, embora de passagem afirme que a ação é direito subjetivo público, parece alhures repelir essa conclusão ao afirmar que o interêsse do titular da ação tem por objeto a justa composição da lide, o que não corresponde à realidade. $O$ autor sem direito e sem razão não tem, é claro, interêsse à justa composição da lide.

A brilhante formulação do problema feita por Pekelis seria, a nosso ver, suficiente para levá-lo a conclusões a que infelizmente não chegou.

"E nisto está" - transcrevemos agora - "a fôrça e a fraqueza do direito subjetivo a um determinado com-

3. Azione, in Nuovo Digesto Italiano. 
portamento do Estado, por êste mesmo desejado, e expresso em uma norma jurídica; a fôrça e a debilidade do direito de ação, que tudo protege e que é protegida sòmente pela necessidade, frágil e poderosa a um tempo, da existência da ordem jurídica. Portanto, o funcionamento do direito de ação é nada mais que o funcionamento do ordenamento jurídico como tal e é a própria consistência do direito (objetivo) considerado pelo ângulo visual do titular do direito (subjetivo). O titular do direito pode, assim, dizer-se o dominus da ação estatal, não no sentido de que tal domínio dependa de uma coercibilidade da ação estatal por parte do particular ou por parte de um superestado, e sim no sentido de que, da norma jurídica, que estabeleceu o nexo entre o querer de um particular e a atividade do Estado, e lhe creou uma certa posição de vantagem, se desprende uma fôrça orgânica e ideal, que é a base do direito e da própria sociedade" ${ }^{4}$.

7. Dito isto, apenas um passo faltaria dar a PeKelis, para negar que aquela certa situação de vantagem fôsse um direito subjetivo. Êsse passo, no entanto, Pekelis não deu. Embora tenha feito a ressalva de que, designar pelo mesmo nome de direito subjetivo a ação e o direito material, seja indice de grave incerteza conceitual, e conquanto tenha afirmado que o diverso significado atribuído à palavra direito torne lògicamente impossível a colocação, em um único sistema de direitos, do direito de ação e do direito subjetivo substancial, reconhece explicitamente à ação o caracter de direito subjetivo do autor.

Entre outras afirmações suas:

"Ao direito de ação bem se adapta o têrmo de direito subjetivo, porque êste não é outro que o direito objetivo subjetivado no momento da dependência do querer de um particular" (id. ib. . $^{\circ} 9$, in fine).

4. id. ib. n. ${ }^{\circ} 9$. 
"Sòmente do particular interessado, mas não daquele que é protegido pelo Estado independentemente de sua vontade, se pode dizer que é êle que age, que a ação do Estado é a sua açâo, que o direito objetivo se torna por um instante seu direito, direito subjetivo" (id. ib. n. ${ }^{\circ} 7$ ).

"A êste grupo pertence, em primeiro lugar, o direito de ação, que pode dizer-se direito subjetivo em sentido próprio ou primário" (id. ib. n. ${ }^{\circ} 12$ ).

"A ação é o único direito subjetivo que realmente cabe ao particular; em relação a êle o chamado direito subjetivo substancial privado é um mero reflexo" (id. ib. n..$^{\circ}$ ).

8. Há grande divergência entre os autores a respeito de quem seja o titular passivo da ação. Para alguns é o Estado (Calamandrei, que a considera direito potestativo; Oskar Bülow, Alfredo Rocco, Ugo Rocco, Marco Tullio ZANZUCGHI, que a consideram direito à atividade dos tribunais; WACH e outros alemães que a consideram direito à tutela jurisdicional). Para outros é a parte contrária, o réu (Chiovenda, que a considera direito potestativo; Savigny, que a considera direito a uma prestação material). Para Carnelutti, é a pessoa física do órgão jurisdicional. Para Liebman, pessoa indeterminada (o ordenamento jurídico).

9. Nenhum dêsses autores deu maior atenção a problema que, a meu ver, deveria preceder a êsse: quem é o titular ativo da ação?

Vamos, para responder a essa questão, submeter o problema à técnica de Carneluttr. Seu sistema, pela coerência, profundeza, integridade e harmonia, prestar-se-á, melhor do que qualquer outro, de método para nossa indagação. Fixemos as noções fundamentais.

Pleiteia-se a prestação jurisdicional como meio de atuar a vontade concreta da lei para a composição do conflito de interêsses. $O$ direito subjetivo é o poder de 
obter proteção da ordem jurídica para determinado interêsse em conflito com o de outrem.

Chamemos, para não precipitar conclusões, de situaçăo jurídica ativa, a ação, atividade necessária para se obter a prestação jurisdicional.

Qual o interêsse protegido pela ação? Segundo CarNELUTTI, o interêsse à justa composição da lide. Quais são os interêsses subordinados? Em primeiro lugar, o interêsse do réu que, na melhor das hipóteses, conseguirá na ação a manutenção do statu quo, e difìcilmente terá compensação suficiente pora o custo, os encargos e os riscos da demanda. Em segundo lugar, o interêsse do autor, que preferiria poder, amparado pela ordem jurídica, utilizar em seu proveito tôdas as fôrças disponíveis, e não apenas a dispendiosa, lenta, incerta e tantas vêzes ineficaz fôrça do aparelho jurisdicional do Estado.

10. A ação é, poìs, a situação jurídica ativa na qual o interêsse à justa e pacífica (pela via jurisdicional) composição do conflito de interesses prevalece sôbre o interêsse do réu à manutenção do statu quo e o interêsse do autor à realização instantanea de seu direito por todos os meios disponíveis.

11 O titular dessa situação jurídica ativa é, e não pode deixar de ser, o Estado, cuja função precípua é precisamente essa, de composição justa e pacífica dos conflitos de interesses. Poder-se-ia então dizer que o Estado é titular de direito público subjetivo contra o autor e o réu? Certamente, não. A possibilidade de agir para satislação de interêsse alheio (a coletividade, no caso) configura o poder jurídico e não o direito subjetivo. Este é a faculdade de agir para proteção de interêsse próprio.

12. Para a realização de seus fins, consubstanciados em preceitos que contêm ordens e proibições, o Estado emprega medidas jurídicas, preventivas e repressivas. 
Quase tôdas as medidas preventivas, e muitas das medidas repressivas, são aplicadas pelo Estado independentemente de qualquer colaboração do particular. O Estado faz, porém, depender da participação do particular a aplicação da maior parte das medidas repressivas (sanções) de caracter reparatório não punitivo. Em outras palavras, a jurisdição civil só funciona mediante a provocação do particular (nemo judex sine actore - ne procedat judex ex officio).

Isso não quer dizer, no entanto, que seja o particular o titular da ação. A ação, poder de fazer predominar sôbre os interesses dos particulares o interêsse à justa e pacífica composição do conflito de interesses, assiste ao Estado. Na propositura da ação, o particular representa o Estado. Daí a bela fórmula de Carnelutti: a ação é exercício privado de função pública.

Também representa o Estado o réu nas exceções em sentido próprio, nas reconvenções e sempre que toma, no processo, a posição do autor, seja quanto aos onus de afirmar e provar, seja quanto ao onus do impulso processual.

13. Nem se diga que seja uma singularidade do direito processual civil essa representação do Estado pelo particular. Não se lhe concede em nome das liberdades públicas o direito de requerer habeas-corpus em favor de quem quer que seja? o particular que se registra candidato a cargos eletivos também não exerce direito próprio apesar de se apresentar para o exercício de funções eminentemente públicas? E os que se apresentam pleiteando registro de partidos políticos?

Há, nessas variadas hipóteses, espécies do gênero "exercício privado de funções públicas”, ou melhor, implícita representação do Estado pelo particular.

14. Detenhâmo-nos, porém, um pouco e analisemos nossas conclusões. Afirmamos que o Estado é o titular 
ativo da situação jurídica que lhe permite impôr ao autor e ao réu a via processual de tutela dos direitos materiais e a seus órgãos a atividade necessária para a entrega $\mathrm{e}$ o cumprimento da prestação jurisdicional. E adiantamos que o Estado não tem direito subjetivo. Tratar-se-ia de direito subjetivo se fôsse seu o interêsse protegido. Não se pode, porém, dizer que o seja. É da coletividade, não do Estado enquanto tal, o interêsse à justa e pacífica composição do conflito de interesses materiais.

$\mathrm{E}$ do lado passivo da situação jurídica, que vemos?

Em primeiro lugar, o juiz, o escrivão, o oficial de justica, o distribuidor, o contador, o pessoal da Secretaria dos iribunais, todo o pessoal do juízo, que, em virtude da relação de emprêgo, deve colaborar na tarefa de entrega da prestação jurisdicional.

Em seguida, o autor, que tem, como condição da tutela jurisdicional pretendida, o onus fundamental de representar o Estado no exercício do poder de ação de que êste é titular, e, como condição de procedência da ação e satisfação de seu interêsse material, o onus de afirmar, alegar, provar e convencer o órgão jurisdicional.

Finalmente, o autor originàriamente, e dépois eventualmente também o réu, que têm, entre si distribuidos alternativamente o onus da parte do impulso processual que não está a cargo do próprio juízo. 